\title{
INFLUENCE OF DIFFERENT FACTORS ON MOMENTUM TRANSFER IN MECHANICALLY AGITATED MULTIPHASE SYSTEMS
}

\author{
Magdalena Cudak, Anna Kiełbus-Rąpała, Marta Major-Godlewska, Joanna Karcz* \\ West Pomeranian University of Technology, Szczecin, Faculty of Technology and Chemical \\ Engineering, al. Piastów 42, 71-065 Szczecin, Poland
}

Dedicated to Prof. Ryszard Pohorecki on the occasion of his 80th birthday

\begin{abstract}
A comparative analysis concerning the influence of different factors on momentum transfer in mechanically agitated systems was carried out on the basis of experimental results for solid-liquid, gas-liquid and gas-solid-liquid systems. The effects of the impeller - baffles system geometry, scale of the agitated vessel, type and number of impellers and their off-bottom clearance, as well as physical properties of the multiphase systems on the critical impeller speeds needed to produce suspension or dispersion, power consumption and gas hold-up were analysed and evaluated.
\end{abstract}

Keywords: multiphase system, agitated vessel, critical impeller speeds, gas hold-up, power consumption

\section{INTRODUCTION}

Solid-liquid mixing of both settling and floating particles in un-gassed or gassed suspensions is required in many technologies of chemical and food processing, fermentation, polymerisation and wastewater treatment (Harnby et al, 1992; Kamieński, 2004; Paul et al, 2004; Stręk, 1981). In literature, there are many correlations to calculate the critical (minimum) impeller speeds for off-bottom suspension of the particles heavier than the liquid (Kamieński, 2004; Nienow, 1968; Paul et al, 2004; Rieger and Ditl, 1994; Zwietering, 1958). Particles less dense than the liquid will float onto the liquid surface (Etchells, 2001). Dispersion of floating particles in an agitated vessel is more sensitive to direction of the fluid circulation and arrangement and type of the baffles than settling of the particles (Bao et al., 2005; Karcz and Mackiewicz, 2006; 2007; 2009; Ozcan-Taskin, 2006; Ozcan-Taskin and Wei, 2003). Mechanically agitated gas - liquid systems using single or more than one impeller on the common shaft have been intensively tested (Adamiak, 2005; Cudak, 2011; Montante et al, 2006; 2007; Moucha et al., 2003; Nienow and Lilly, 1996; Warmoeskerken, 1986). Power consumption data (Adamiak and Karcz, 2007), gas hold-up (Kamieński and Niżnik, 2001; Karcz et al., 2004) and scaleup effects (Karcz and Siciarz, 2004; Karcz et al., 2007) have been discussed. In agitated three phase systems, gas is dispersed simultaneously with particles suspended in a fluid (Takenaka et al, 2001; Zhu and $\mathrm{Wu}, 2001)$. The agitation of gas -solid - liquid systems have been experimentally analysed in few papers only (Cudak, 2014; Kiełbus-Rąpała and Karcz, 2010; 2012; Kiełbus-Rąpała et al., 2011; MajorGodlewska and Karcz, 2012).

The aim of the study presented in this paper was to analyse the effects of the baffling, impeller type and physical properties of fluid on the critical impeller speed, power consumption and gas hold-up in the 
two- and three-phase systems agitated in the vessels of different scale. A comparative analysis of experimental data was carried.

\section{RANGE OF MEASUREMENTS}

Measurements of the power consumption $P$ and gas hold-up $\varphi$ were carried out in an agitated vessel with the inner diameter $D=0.288 \mathrm{~m}$ or $0.634 \mathrm{~m}$. The vessel equipped with a flat bottom was filled with a liquid up to the height $H=D$ or $H=2 D$ (Fig. 1). One $(i=1)$ or two $(i=2)$ high speed impellers were mounted on the vessel shaft at a distance $h$ measured from the bottom of the vessel. A single impeller ( $i$ $=1)$ was located at a distance $h=0.33 H$ when gas - liquid, solid - liquid $\left(\rho_{\mathrm{p}}>\rho_{\mathrm{L}}\right)$ and gas - solid liquid systems were agitated. In case of the solid - liquid system $\left(\rho_{\mathrm{p}}<\rho_{\mathrm{L}}\right)$, the distance $h$ was equal to $0.67 \mathrm{H}$. Two impellers $(i=2)$ mounted on the common shaft were located at the distances $h_{1}=0.33 \mathrm{H}$ and $h_{2}=0.67 H$, respectively.

Different types of high speeds impellers were used to multiphase system agitation: radial flow Rushton turbine (RT, $\left.Z=6 ; d_{0} / d=0.75 ; a / d=0.25 ; b / d=0.2\right)$, Smith turbine $\left(\mathrm{CD} 6, Z=6 ; d_{0} / d=0.75\right.$; $a / d=0.25 ; b / d=0.2 ; R / b=0.5)$, turbine $\left(T, Z=6 ; b / d=0.2 ; \beta=90^{\circ}\right)$, mixed flow up- and down pumping pitched blade turbines (PBT $\uparrow$, PBT $\left.\downarrow, Z=6 ; b / d=0.2 ; \beta=60^{\circ} ; \beta=45^{\circ}\right)$, A $315(d / D=0.33$ or $0.5 ; Z=4)$ and axial flow up- and down pumping propellers ( $\mathrm{P} \uparrow, \mathrm{P} \downarrow, Z=3 ; S / d=1)$, as well as down pumping HE 3 impeller $(d / D=0.33$ or $0.5 ; Z=3)$. In case of the system of two impellers on the common shaft, Rushton and Smith turbines were used as lower impellers, whereas Rushton turbine, propeller, HE 3, A 315 impellers were located at the upper position. An agitated vessel was equipped with planar or tubular baffles.

a)

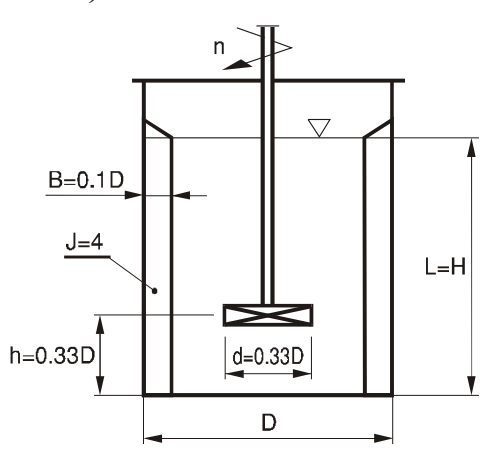

d)

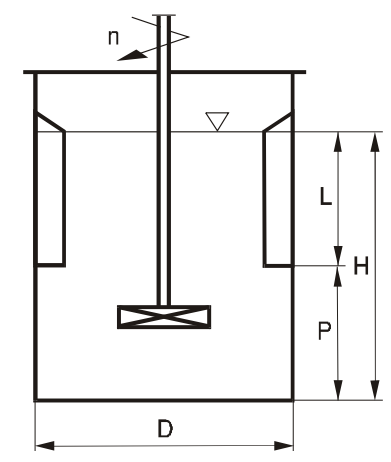

b)

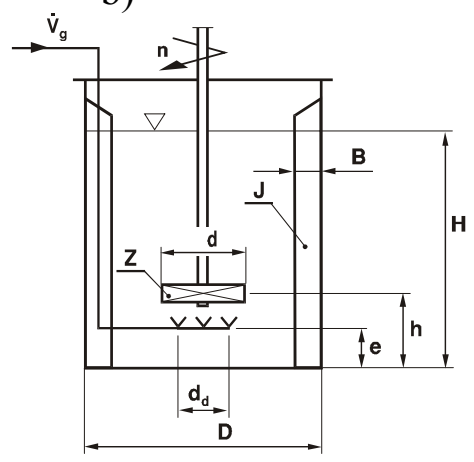

e)

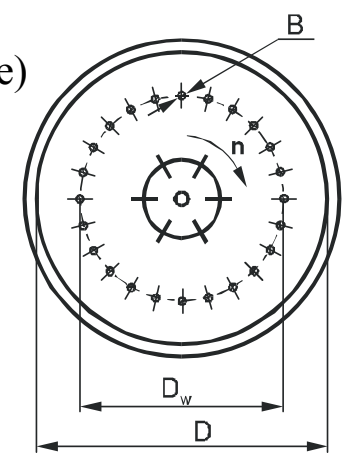

c)

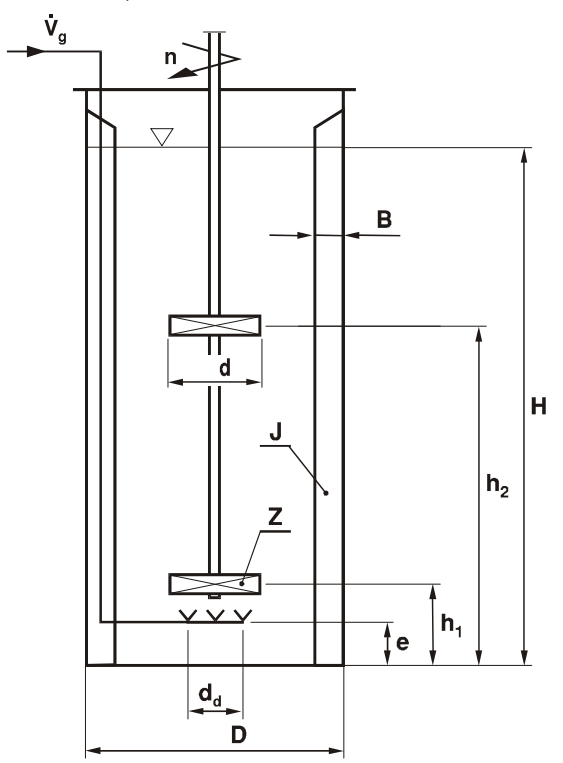

Fig. 1. Geometrical parameters of the baffled agitated vessels used in the study;

a) standard geometry of the vessel with planar baffles $(H / D=1)$; b) vessel with planar baffles and gas sparger $(i=1 ; H / D=1) ; \mathrm{c})$ vessel with planar baffles and gas sparger $(i=2 ; H / D=2)$; d) vessel with short planar baffles $(i=1 ; H / \mathrm{D}=1) ; \mathrm{e})$ vessel with tubular baffles $(i=1 ; H / D=1)$ 
Geometrical systems with standard planar baffles (number of baffles $J=4$; length of baffle $L=H$; width of baffle $B=0.1 D$ ) located in the agitated vessels with single or two impellers, as well as nonstandard ones $(0<J \leq 4 ; B=0.1 D$; $L$, where $p+L=H)$ in the vessel with single impeller were tested. Tubular baffles consisted of the $J=24$ pipes of outer diameter $B=0.016 D$ and length $L=H$. The pipes were arranged on the mean coil diameter $D_{\mathrm{c}}=0.7 \mathrm{D}$. Gas was introduced into the liquid through a ring-shaped sparger of diameter $d_{\mathrm{d}}=0.7 d$ which was located at a distance of $e=h / 2$ (or $\left.h_{1} / 2\right)$ from the bottom of the vessel.

Distilled water and aqueous solutions of: electrolytes, glucose, glycerol and sucrose with different mass concentration were used in the experiments. Air was applied as a gas phase. Sea sand and polyethylene particles were used as the solid phase. The range of measurements is given in Table 1. Measurements were carried out within the turbulent regime of the liquid flow in the agitated vessel.

Table 1. Range of the measurements

\begin{tabular}{|c|c|c|c|c|}
\hline System & $D, \mathrm{~m}$ & Impeller & Baffles & Range \\
\hline $\begin{array}{l}\text { Solid - } \\
\text { liquid; } \\
\rho_{\mathrm{p}}>\rho_{\mathrm{L}}\end{array}$ & 0.295 & $\begin{array}{l}\mathrm{RT} ; \\
\operatorname{PBT} \uparrow\left(\beta=45^{\circ}\right) \\
\mathrm{P} \uparrow(S / d=1)\end{array}$ & $\begin{array}{l}\text { planar; } J=4 ; \\
B / D=0.1 ; \\
p+L=H ; p / H \\
\in \leq 0 ; 0.67\end{array}$ & $\begin{array}{l}i=1 ; H / D=1 ; d / D=0.33 ; h / D=0.33 ; \\
\text { liquid: distilled water; } \\
\text { solids: sea sand particles: } d_{\mathrm{p}}=250 \mu \mathrm{m} ; \\
\rho_{\mathrm{p}}=2470 \mathrm{~kg} / \mathrm{m}^{3} ; X=2.5 ; 5 ; 7.5 ; 10 \%\end{array}$ \\
\hline $\begin{array}{l}\text { Solid - } \\
\text { liquid; } \\
\rho_{\mathrm{p}}<\rho_{\mathrm{L}}\end{array}$ & $\begin{array}{l}0.295 \\
0.634\end{array}$ & $\begin{array}{l}\mathrm{RT} ; \\
\mathrm{PBT} \downarrow \text { or } \mathrm{PBT} \uparrow \\
\left(\beta=45^{\circ}\right) ; \mathrm{P} \uparrow\end{array}$ & $\begin{array}{l}\text { planar; } \\
0 \leq \leq J \leq 4 ; B / D \\
=0.1 ; p+L= \\
\mathrm{H} ; \\
0.25 \leq L / H \leq 1\end{array}$ & $\begin{array}{l}i=1 ; H / D=1 ; d / D=0.33 ; h / D=0.67 \\
\text { liquid: distilled water; } \\
\text { solids: polyethylene particles; } d_{\mathrm{p}}=4.5 \mathrm{~mm} ; \\
\rho_{\mathrm{p}}=952 \mathrm{~kg} / \mathrm{m}^{3} ; 1 \%<X<4 \% \\
10^{4} \leq \operatorname{Re} \leq 9 \times 10^{4} ;\end{array}$ \\
\hline $\begin{array}{l}\text { Gas - } \\
\text { liquid }\end{array}$ & $\begin{array}{l}0.288 \\
0.634\end{array}$ & $\begin{array}{l}\text { RT; CD 6; } \\
\text { A } 315 \\
\text { RT + RT* } \\
\text { CD } 6+\text { P }^{*} \\
\text { CD } 6+\mathrm{RT}^{*} \\
\text { RT + A } 315^{*} \\
\text { RT + P }{ }^{*} \\
\text { RT + HE } 3^{*} \\
{ }^{*} \text { upper }\end{array}$ & $\begin{array}{l}\text { planar; } \\
J=4 \\
L / H=1 \\
B / D=0.1\end{array}$ & $\begin{array}{l}i=1 \text { or } 2 ; H / D=1 \text { or } 2 ; d / D=0.33 ; \\
h_{1} / H=0.33 ; h_{2} / H=0.67 ; \\
\text { liquid: distilled water, aqueous solution of } \\
30 \% \text { glucose; aqueous solutions of } \mathrm{NaCl} \\
(1<Y \leq 1.6) ; \text { glycerol solutions; solutions of } \\
40,60 \text { and } 70 \% \text { starch sirup; } 1000 \leq \rho_{\mathrm{L}}\left[\mathrm{kg} / \mathrm{m}^{3}\right] \\
\leq 1258 ; 1 \leq \eta \times 10^{3}[\mathrm{~Pa} \cdot \mathrm{s}] \leq 32.5 ; 0.072 \leq \sigma \\
{[\mathrm{N} / \mathrm{m}] \leq 0.095 ; \text { gas: air; } w_{\mathrm{og}} \leq 5.1 \times 10^{-3} \mathrm{~m} / \mathrm{s},} \\
3 \times 10^{4} \leq \operatorname{Re} \leq 2 \times 10^{5} ;\end{array}$ \\
\hline $\begin{array}{l}\text { Gas - } \\
\text { liquid }\end{array}$ & 0.634 & $\begin{array}{l}\text { A } 315 \\
\text { T }\left(\beta=90^{\circ}\right) ; \\
\operatorname{PBT} \uparrow\left(\beta=60^{\circ}\right) ; \\
\operatorname{PBT} \uparrow\left(\beta=45^{\circ}\right) ;\end{array}$ & $\begin{array}{l}\text { tubular; } \\
J=24 \\
B / D=0.016 \\
L / H=1 \\
D_{\mathrm{c}} / D=0.7\end{array}$ & $\begin{array}{l}i=1 ; H / D=1 ; d / D=0.33 ; h / D=0.33 ; \\
\text { liquid: distilled water; aqueous solutions of } \\
\mathrm{NaCl}(1<Y \leq 1.6) ; \\
\text { gas: air; } 1.76 \leq w_{\mathrm{og}} \times 10^{3}[\mathrm{~m} / \mathrm{s}] \leq 5.1 \\
2.1 \times 10^{5}<\operatorname{Re}<4 \times 10^{5} ;\end{array}$ \\
\hline $\begin{array}{l}\text { Gas - } \\
\text { solid - } \\
\text { liquid } \\
\rho_{\mathrm{p}}<\rho_{\mathrm{L}}\end{array}$ & $\begin{array}{l}0.295 \\
0.634\end{array}$ & $\begin{array}{l}\mathrm{RT} \\
\mathrm{PBT} \downarrow \text { or } \mathrm{PBT} \uparrow \\
\left(\beta=45^{\circ}\right) ;\end{array}$ & $\begin{array}{l}\text { planar; } J=4 \\
L / H=1 \\
B / D=0.1\end{array}$ & $\begin{array}{l}i=1 ; H / D=1 ; d / D=0.33 ; h / D=0.33 \\
\text { liquid: distilled water; } \\
\text { solids: polyethylene particles; } d_{\mathrm{p}}=4.5 \mathrm{~mm} ; \\
\rho_{\mathrm{p}}=952 \mathrm{~kg} / \mathrm{m}^{3} ; 1 \%<X<4 \% ; \text { gas: air; } \\
w_{\mathrm{og}} \leq 4 \times 10^{-3} \mathrm{~m} / \mathrm{s} ; \quad 10^{4} \leq \operatorname{Re} \leq 9 \times 10^{4}\end{array}$ \\
\hline $\begin{array}{l}\text { Gas - } \\
\text { solid - } \\
\text { liquid } \\
\rho_{\mathrm{p}}>\rho_{\mathrm{L}}\end{array}$ & 0.634 & $\begin{array}{l}\text { RT; CD } 6 ; \\
\text { A } 315(d / D= \\
0.33 \text { or } 0.5) \\
\text { HE } 3(d / D= \\
0.33 \text { or } 0.5)\end{array}$ & $\begin{array}{l}\text { planar; } J=4 ; \\
L / H=1 \\
B / D=0.1\end{array}$ & $\begin{array}{l}i=1 ; H / D=1 ; d / D=0.33 \text { or } 0.5 ; h / D=0.33 ; \\
\text { liquid: distilled water; aqueous solutions of } \\
\mathrm{NaCl}(1<Y \leq 1.6) ; \text { gas: air; } w_{\mathrm{og}} \leq 4 \times 10^{-3} \mathrm{~m} / \mathrm{s} \text {; } \\
Q_{\mathrm{GV}} \leq 0.5\left(\mathrm{~m}^{3} / \mathrm{min}\right) / \mathrm{m}^{3} ; \text { solids: sea sand; } \\
d_{\mathrm{p}}=335 \mu \mathrm{m} ; \rho_{\mathrm{p}}=2600 \mathrm{~kg} / \mathrm{m}^{3} ;\end{array}$ \\
\hline $\begin{array}{l}\text { Gas - } \\
\text { solid - } \\
\text { liquid } \\
\rho_{\mathrm{p}}>\rho_{\mathrm{L}}\end{array}$ & 0.288 & $\begin{array}{l}\mathrm{RT}+\mathrm{A} 315^{*} \\
\mathrm{RT}+\mathrm{HE} 3^{*} \\
{ }^{*} \text { ) upper }\end{array}$ & $\begin{array}{l}\text { planar; } J=4 ; \\
L / H=1 ; \\
B / D=0.1\end{array}$ & $\begin{array}{l}i=2 ; H / D=2 ; d / D=0.33 ; h_{1} / H=0.33 ; \\
h_{2} / H=0.67 ; \text { liquid: distilled water; aqueous } \\
\text { solutions of } \mathrm{NaCl}(1<Y \leq 1.6) ; \text { gas: air; solids: } \\
\text { sea sand; } d_{\mathrm{p}}=335 \mu \mathrm{m} ; X<2.5 \% \text { mass; } \\
8 \times 10^{4} \leq \operatorname{Re} \leq 1.6 \times 10^{5} ;\end{array}$ \\
\hline
\end{tabular}


Video technique and computer image acquisition system were used to record the different states of the suspension $\left(\rho_{\mathrm{p}}>\rho_{\mathrm{L}}\right)$, which were observed through the transparent flat bottom of the agitated vessel. Critical impeller speeds $n_{\mathrm{JS}}$ (or $n_{\mathrm{JSG}}$ in case of the gas - solid - liquid system), required to achieve the state at which particles just become suspended in a liquid (or in a gas - liquid dispersion), were determined according to Zwietering criterion (Stręk, 1981), i.e., there are such impeller speeds at which no particles stayed longer than $2 \mathrm{sec}$ at the vessel bottom. A computer - aided digital camera was used to record different stages of floating particles $\left(\rho_{\mathrm{p}}<\rho_{\mathrm{L}}\right)$ suspension in a liquid or in a gas - liquid dispersion. Just drawn down impeller speeds $n_{\mathrm{JD}}$ (or $n_{\mathrm{JDG}}$ in a gas - liquid dispersion) were defined analogously to Zwietering criterion, i. e. there are such impeller speeds at which no particles stayed longer than $2 \mathrm{sec}$ at the free surface of the liquid.

The power consumption was measured using the strain gauge method (Adamiak and Karcz, 2007). Gas hold-up was calculated from Equation (1)

$$
\varphi=\frac{H_{g}-H}{H_{g}}
$$

The averaged value of gas hold-up was determined from 10 readings of the gas-liquid mixture height in the agitated vessel.

\section{RESULTS AND DISCUSSION}

The results of the experiments performed for solid - liquid system show that baffling and impeller type affect significantly critical impeller speeds $n_{\mathrm{JS}}$ and energy dissipated $n_{\mathrm{JS}}$ in an agitated system. In Fig. 2, both stages of a particle suspension produced in an agitated vessel equipped with a standard Rushton turbine $(h / D=0.33)$ and four planar baffles $(B / D=0.1)$ are presented for a constant value of the impeller speed $n=8.331 / \mathrm{s}$ and particle concentration $X=2.5 \%\left(d_{\mathrm{p}}=250 \mu \mathrm{m} ; \rho_{\mathrm{p}}=2470 \mathrm{~kg} / \mathrm{m}^{3}\right)$.

a)

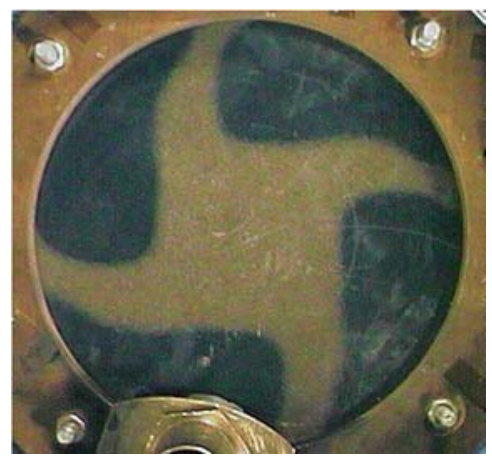

b)

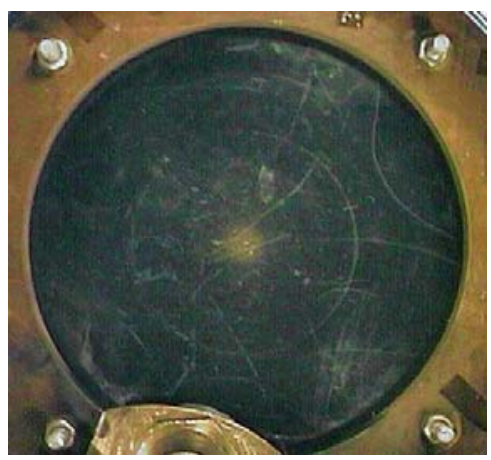

Fig. 2. Image of the agitated vessel bottom; Rushton turbine (RT) and planar baffles; sea sand - water system; $D=0.295 \mathrm{~m} ; i=1 ; H / D=1 ; h / D=0.33 ; n=8.331 / \mathrm{s} ; d_{\mathrm{p}}=250 \mu \mathrm{m} ; \rho_{\mathrm{p}}=2470 \mathrm{~kg} / \mathrm{m}^{3} ; X=2.5 \%$ mass.; a) $p / H=0$; b) $p / H=0.5$

The baffle off-bottom clearance $p$ was equal to $0(L=H$, Fig. $2 \mathrm{a})$ or 0.5 ( $L=0.5 H$, Fig. $2 \mathrm{~b})$. A comparison shows that particles are better suspended in the agitated vessel with short planar baffles (Fig. 2b, no particles occupying vessel bottom).

In the vessel with four standard planar baffles, particles create at the vessel bottom a characteristic shape of a rosette at the edges of the baffles. The effect of the geometrical parameter $p / H$ on the Froude number $F r_{\mathrm{JS}}\left(=n_{\mathrm{JS}}{ }^{2} d / g\right)$ was determined on the basis of experimental data obtained for the agitated 
vessel of inner diameter $D=0.295 \mathrm{~m}$. The effect was given in Eq. (2) (Table 2) within the range of the geometrical parameters listed in line 1 of the Table 1 . The effect of the geometrical parameter $\mathrm{p} / \mathrm{H}$ on the Froude number $F r_{\mathrm{JS}}$ and energy dissipated $\varepsilon_{\mathrm{JS}}$ expressed in W/kg is compared in Fig. 3 for three different high speed impellers. As the data in Fig. 3a show, the dependence $F r_{\mathrm{JS}}=f(p / H)$ strongly diminishes with the increase of $p / H$ for an agitated vessel with a radial flow Rushton turbine (Eq. (2), Table 2). For example, it is over 2.5 times for $p / H=0.5$ related to the standard baffles $(L / H=1$; $p / H=0)$. The effect of the $p / H$ on the Froude number $F r_{\mathrm{JS}}$ is lesser for the mixed flow down pumping PBT impeller and, especially, axial flow down pumping propeller. Mean energy dissipated $\varepsilon_{\mathrm{Js}}$ corresponding to critical impeller speeds $n_{\mathrm{JS}}$, depends on the impeller type and $p / H$ parameter (Fig. $3 \mathrm{~b}$ ). The highest level of energy dissipated is ascribed to the Rushton turbine and, assuming $p / H=0.5$, it is about four times higher than that for the pitched blade turbine and propeller.

The effect of baffling and impeller type on critical impeller speeds in a solid - liquid system should be also considered in terms of particle density $\rho_{\mathrm{p}}$. In case of floating particles $\left(\rho_{\mathrm{p}}<\rho_{\mathrm{L}}\right)$, the clearance $h$ between the impeller and vessel bottom plays an important role in the drawdown of the particles.

a)

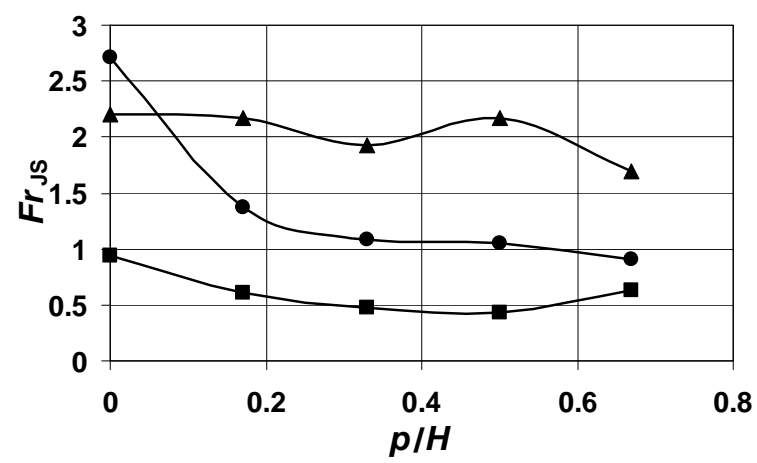

b)

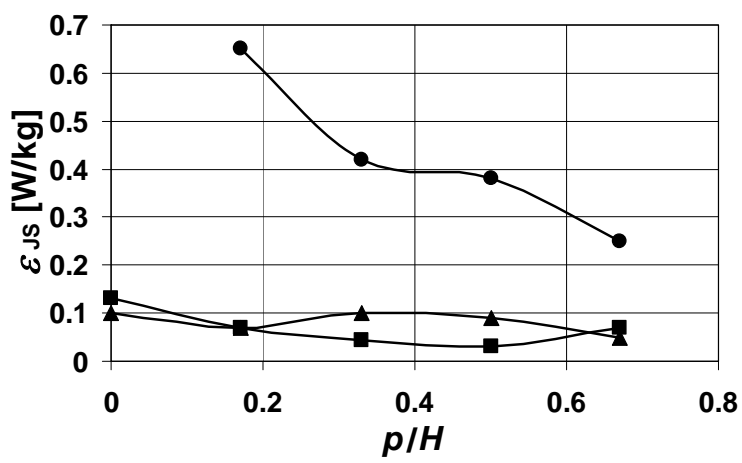

Fig. 3. The dependence a) $F r_{\mathrm{JS}}=f(p / H) ;$ b) $\varepsilon_{\mathrm{JS}}=f(p / H)$ for different impellers and planar baffles; $D=0.295 \mathrm{~m}$; $i=1 ; d / D=0.33 ; h / D=0.33 ; H / D=1 ; J=4 ; B / D=0.1 \bullet-\mathrm{RT} ; \boldsymbol{\Delta}-\mathrm{P} \downarrow, Z=3 ; \bullet-\mathrm{PBT} \downarrow, \beta=45^{\circ}, Z=6$

a)

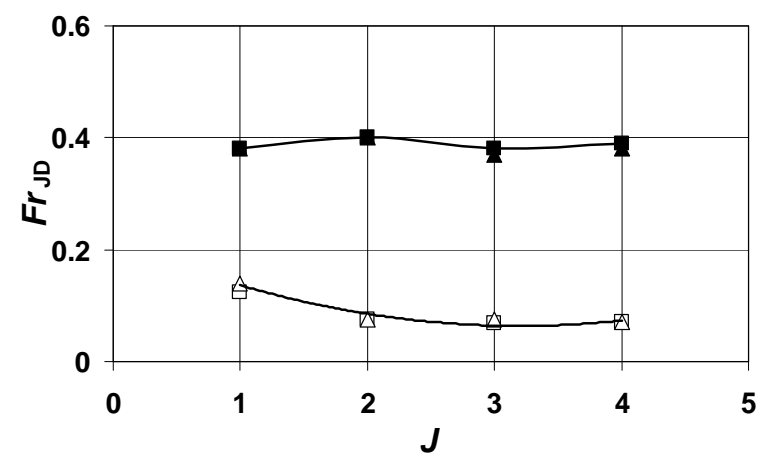

b)

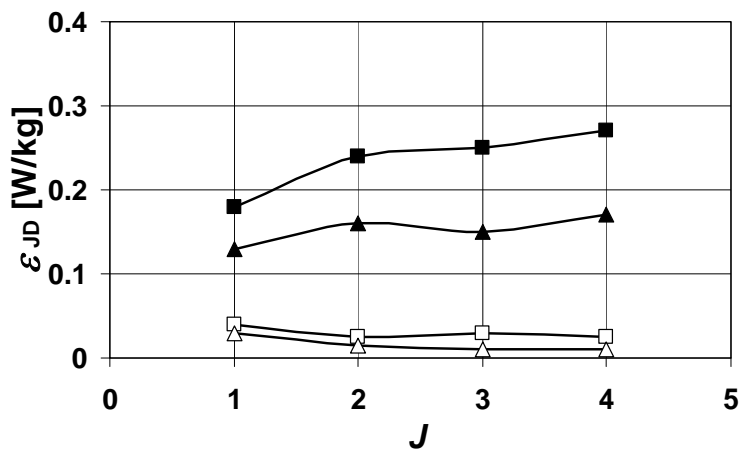

Fig. 4. The dependence a) $F r_{\mathrm{JD}}=f(J)$; b) $\varepsilon_{\mathrm{JD}}=\mathrm{f}(J)$ for PBT $\uparrow$ for different vessel diameter and $h / D$ ratio; planar baffles; $H / D=1 ; i=1 ; \square-D=0.634 \mathrm{~m} ; h=0.33 D ; \boldsymbol{\Delta}-D=0.295 \mathrm{~m} ; h=0.33 D ; \square-D=0.634 \mathrm{~m} ; h=0.67 D$; $\Delta-D=0.295 \mathrm{~m} ; h=0.67 D$

Experimental data for a suspension of floating particles, obtained for an up-pumping pitched blade turbine and a different number of planar baffles $J$ of full length $L(L=H)$, are presented in Fig. 4 (Eqs. (3) and (4) for $D=0.295 \mathrm{~m}$, Table 2). The dependencies $F r_{\mathrm{JD}}=f(J)$ and $\varepsilon_{\mathrm{JD}}=f(J)$ are compared for both values of the height $h=0.33 D$ or $h=0.67 D$ and both values of inner diameter of the agitated vessel $D=0.295 \mathrm{~m}$ or $0.634 \mathrm{~m}$ (corresponding to working volume of $20 \mathrm{dm}^{3}$ or $200 \mathrm{dm}^{3}$, respectively). The results in Fig. 4 show that the geometrical parameters ratio $h / D=0.67$ should be recommended in 
this case because the values of $F r_{\mathrm{JD}}$ and $\varepsilon_{\mathrm{JD}}$ are significantly smaller than those for $h / D=0.33$. Moreover, the baffle number $J$ and scale of the agitated vessel affect weakly the just drawn down impeller speed $n_{\mathrm{JD}}$ compared to the effect of the geometrical parameter $h / D$.

$P$

a)

b)
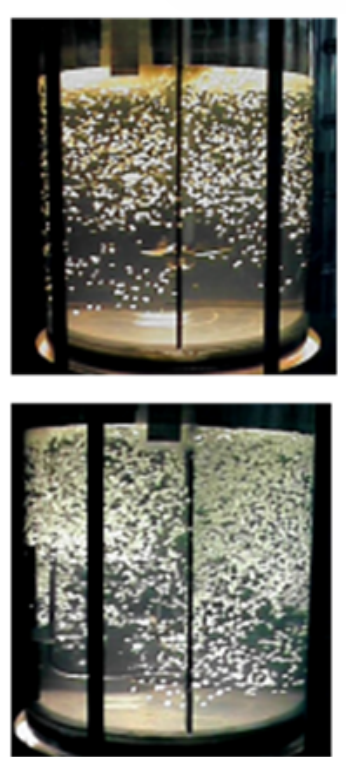

$\operatorname{PBT} \uparrow$
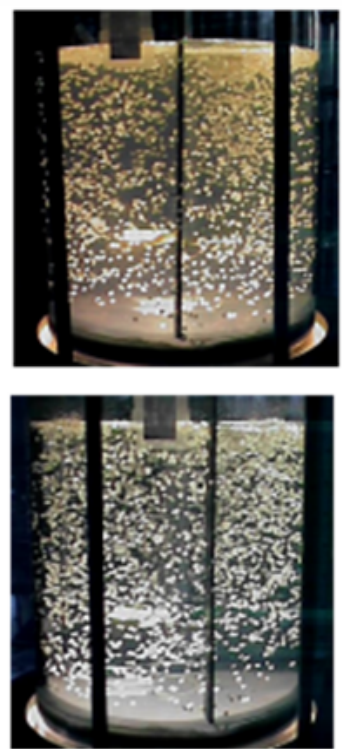

PBT $\downarrow$
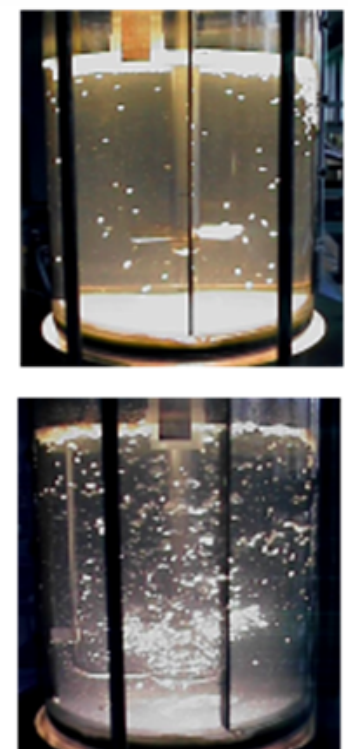

\section{RT}
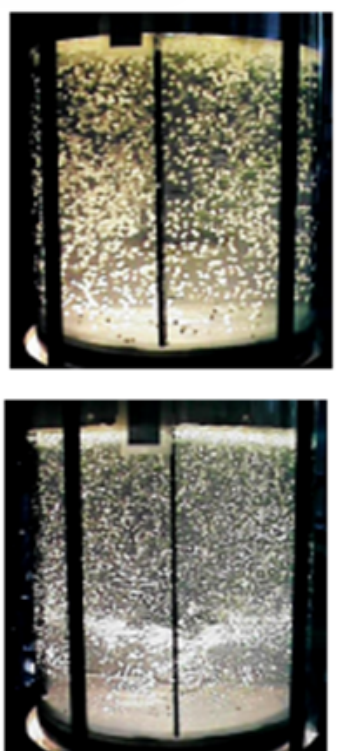

Fig. 5. Comparison of the capability of different agitators (P, PBT $\uparrow, \mathrm{PBT} \downarrow$, RT) to disperse floating particles $\left(\rho_{\mathrm{p}}<\rho_{\mathrm{L}}\right)$ in a liquid; $D=0.295 \mathrm{~m} ; H / D=1 ; h / D=0.33$; planar baffles; $J=4 ; L / H=1 n=4,161 / \mathrm{s} ; X=1 \%$ mass.; a) solid - liquid system, $\left.w_{\mathrm{og}}=0 \mathrm{~m} / \mathrm{s} ; \mathrm{b}\right)$ gas - solid - liquid system, $w_{\mathrm{og}}=7 \times 10^{-4} \mathrm{~m} / \mathrm{s}$

A comparison of the capability to disperse floating particles in a liquid by means of different impellers in a vessel with four standard planar baffles (Fig. 5a) reveals that a proper choice of an impeller is the key factor . Using an up-pumping pitched blade turbine (PBT $\uparrow$ ) or a Rushton turbine (RT) located at the height $h=0.33 D$, good dispersion of a floating particles $\left(\rho_{\mathrm{p}}<\rho_{\mathrm{L}}\right)$ in a liquid can be obtained, whereas a down-pumping pitched blade turbine (PBT $\downarrow$ ) should not be recommended for this purpose. However, the reverse is true when a gas phase is added into a solid - liquid system (Fig. 5b), through a gas sparger, located under the impeller. The best effects of simultaneous dispersion of both solid and gas phases in a liquid phase can be provided by an up-pumping pitched blade turbine (PBT $\uparrow$ ).

A propeller (P) and a down-pumping pitched blade turbine (PBT $\downarrow$ ) can slightly better disperse simultaneously both floating particles and gas bubbles into a liquid (Fig. 5b) compared to a solid liquid system (Fig. 5a).

Effects of the superficial gas velocity $w_{\mathrm{og}}$ and solid concentration $X$ on the critical impeller speed $n_{\mathrm{JS}}$ and $n_{\mathrm{JSG}}$, expressed by means of the dimensionless $F r_{\mathrm{JS}}$ and $F r_{\mathrm{JSG}}$ numbers, are presented in Figs. 6a and 7a. The results were obtained for an agitated vessel differing in liquid volume (Fig. 6a, $D=0.288 \mathrm{~m}$; Fig. 7a, $D=0.634 \mathrm{~m}$ ) and equipped with a Rushton turbine (RT), a Smith turbine (CD 6) or an A 315 impeller. In Figs. 6 and 7, data for two values of particle concentration $X$ are compared.

In a smaller agitated vessel (Fig. 6a), the greatest increase of the function $\operatorname{Fr}_{\mathrm{JSG}}=f\left(w_{\mathrm{og}}\right)$ is observed for the Rushton turbine (RT). For each impeller, the function increases with the increase of particle concentration $X$. Among impellers operating in the larger agitated vessel $(D=0.634 \mathrm{~m}$, Fig. 7a), the highest values of the function $F r_{\mathrm{JSG}}=f\left(w_{\mathrm{og}}\right)$ correspond to the CD 6 impeller. The specific agitation energy $\varepsilon_{\text {JSG }}$ can be recognised as better than $F r_{\text {JSG }}$ criterion to compare different effects of agitated vessel geometry on the production of possibly uniformly dispersed multiphase systems. The data $\varepsilon_{\mathrm{JSG}}=f\left(w_{\mathrm{og}}\right)$ in Figs. $6 \mathrm{~b}$ and $7 \mathrm{~b}$ (Eq. (10), Table 2$)$ show that the highest agitation energy is needed for 
the Rushton turbine operating in the smaller vessel (Fig. 6b), as well as the CD 6 impeller in the larger vessel (Fig. 7b). For both agitated vessels, the lowest value of the $\varepsilon_{\text {ISG }}$ corresponds to the A 315 impeller.

a)

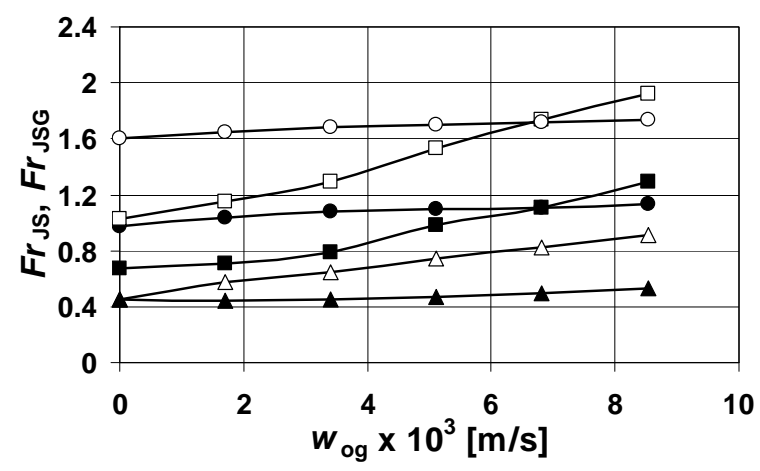

b)

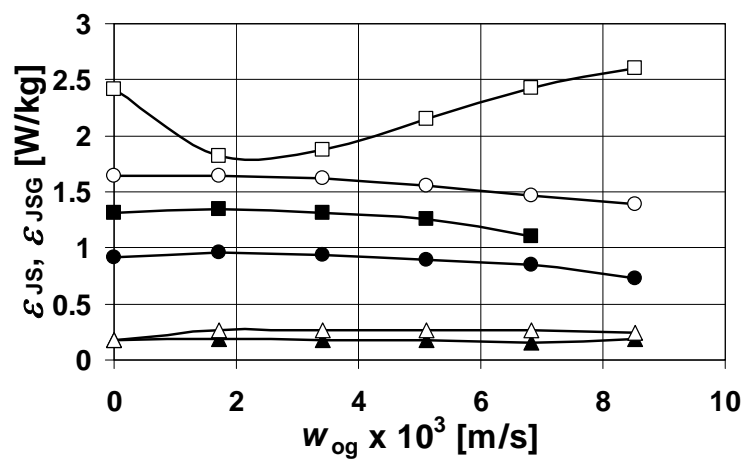

Fig. 6. The dependence a) $F r_{\mathrm{JS}}, F r_{\mathrm{JSG}}=f\left(w_{\mathrm{og}}\right) ;$ b) $\varepsilon_{\mathrm{JS}}, \varepsilon_{\mathrm{JSG}}=f\left(w_{\mathrm{og}}\right)$ for different impellers;

-, $\square$ - RT; $\bullet, \circ-\mathrm{CD} 6 ; \boldsymbol{\Lambda}, \Delta-\mathrm{A} 315$; filled points $-X=0.5 \%$ mass.; empty points $-X=2.5 \%$ mass.; $D=0.288 \mathrm{~m} ; i=1 ; H / D=1 ; h / D=0.33$; planar baffles; $J=4 ; B / D=0.1$

a)

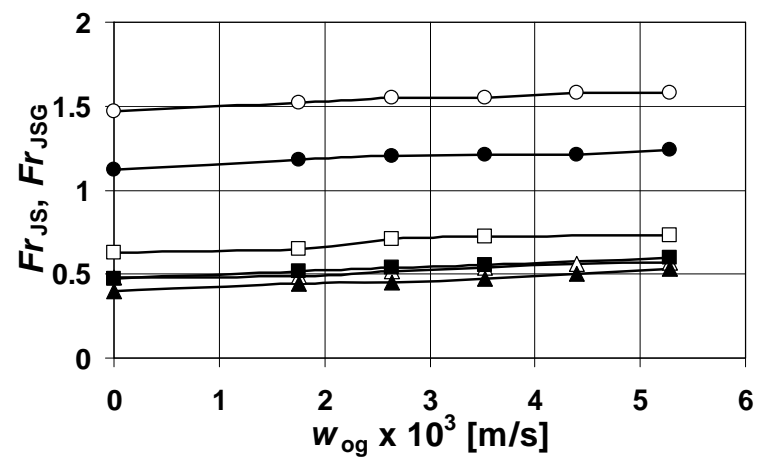

b)

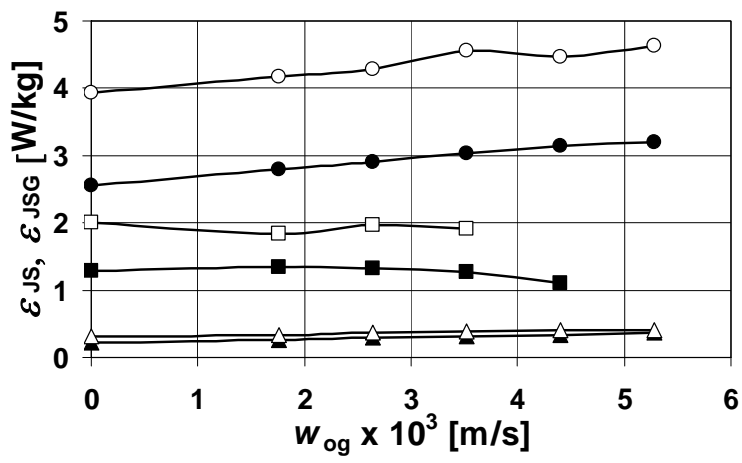

Fig. 7. The dependence a) $F r_{\mathrm{JS}}, F r_{\mathrm{JSG}}=f\left(w_{\mathrm{og}}\right)$; b) $\varepsilon_{\mathrm{JS}}, \varepsilon_{\mathrm{JSG}}=f\left(w_{\mathrm{og}}\right)$ for different impellers;

-, $\square$ - RT; $\bullet, \circ-\mathrm{CD} 6$; $\boldsymbol{\Delta}, \Delta-\mathrm{A} 315$; filled points $-X=1 \%$ mass.; empty points $-X=2.5 \%$ mass.; $D=0.634 \mathrm{~m} ; i=1 ; H / D=1 ; h / D=0.33$; planar baffles; $J=4 ; B / D=0.1$

The presence of the gas phase in a liquid usually leads to a significant decrease of power consumption compared to that for the liquid phase (Eqs. (5), (6) and (8) in Table 2). Power characteristics $P_{\mathrm{g}} / P_{\mathrm{o}}=$ $\mathrm{f}(\mathrm{Kg})$ are presented for different geometrical and physical parameters of gas - liquid (Fig. 8a) and gas - solid - liquid systems (Fig. 8b).

Gas flow number $K g=V_{\mathrm{g}} / n d^{3}$ and $P_{\mathrm{o}}$ denotes power consumption for the liquid phase only. In Fig. 8a, power curves are compared for an agitated vessel with tubular baffles and one of the following impellers: turbine $\left(\mathrm{T}, \beta=90^{\circ}\right)$, up pumping pitched blade turbine PBT $\uparrow\left(\beta=45^{\circ}\right)$ or A 315 impeller. The power curves in Fig. 8a were prepared on the basis of Eqs. (6) and (8) (Major-Godlewska and Karcz, 2003, 2011) for given values of the Froude number $F r=n^{2} d / g$. The greatest decrease in $P_{\mathrm{g}} / P_{\mathrm{o}}$ with increasing $K g$ values corresponds to the turbine, whereas the lowest one - to the A 315 impeller. Experimental data presented in Fig. 8b show that power characteristics $P_{\mathrm{g}} / P_{\mathrm{o}}=f(K g)$ for a gas - solid liquid system agitated in a vessel with planar baffles depend slightly only on particle concentration $X$, but the impact of the impeller type is differentiated. For the radial flow Rushton turbine, $P_{\mathrm{g}} / P_{\mathrm{o}}$ values fall radically with the increasing gas flow number $K g$, whereas $P_{\mathrm{g}} / P_{\mathrm{o}}$ values remain practically constant for the A 315 impeller within the range of measurements. 
a)

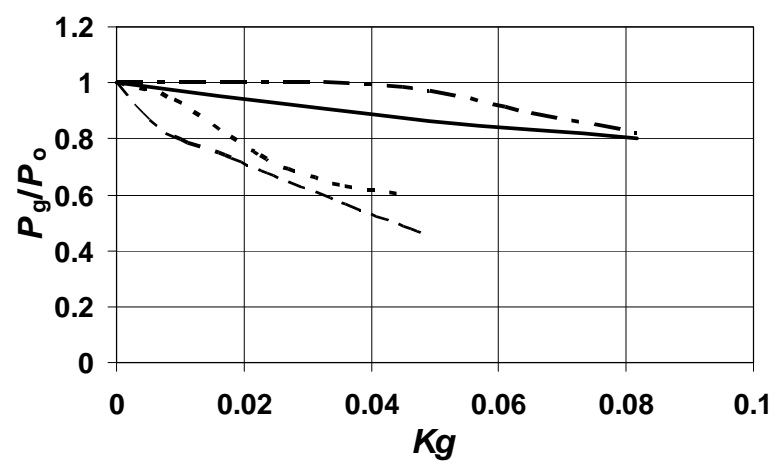

b)

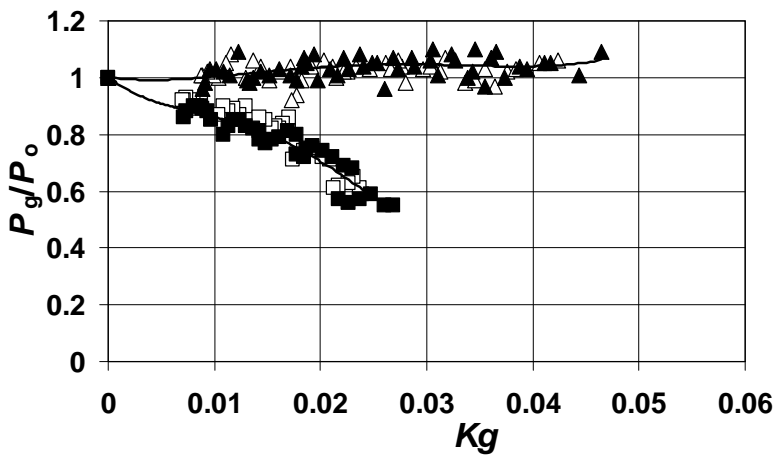

Fig. 8. Power characteristics $P_{\mathrm{g}} / P_{\mathrm{o}}=f(K g) ; D=0.634 \mathrm{~m} ; i=1 ; H / D=1 ; d / D=0.33 ; h / D=0.33$;

a) air - water system, tubular baffles, $J=24, B / D=0.016, L / H=1, D_{\mathrm{c}} / D=0.7$;

- - - - turbine $\left(\beta=90^{\circ}\right), F r=0.95 ; \cdots \cdots \cdots-\operatorname{PBT} \uparrow\left(\beta=45^{\circ}\right), F r=0.95 ;-\cdots-\cdots-A ~ 315, F r=0.29$;

b) gas - solid - liquid system, planar baffles; aqueous solution of electrolyte, $Y=1.36$;

- $-\mathrm{RT}, X=1 \%$ mass.; $\square$ - RT, $X=2.5 \%$ mass.; $\boldsymbol{\Delta}$ - A 315, $X=1 \%$; $\Delta$ - A 315, $X=2.5 \%$ mass.

a)

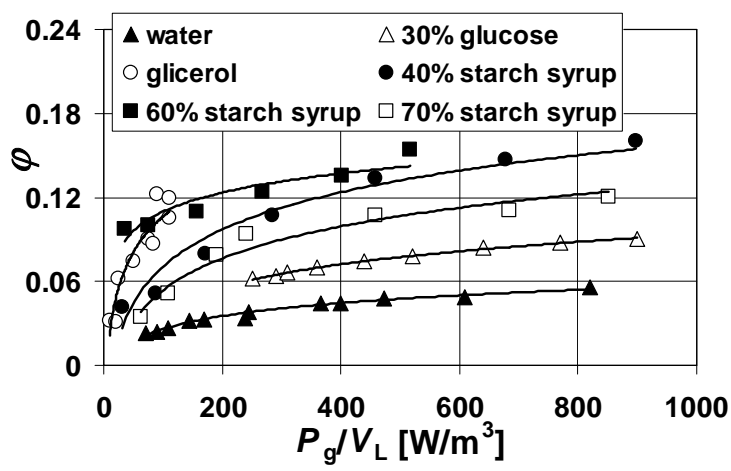

b)

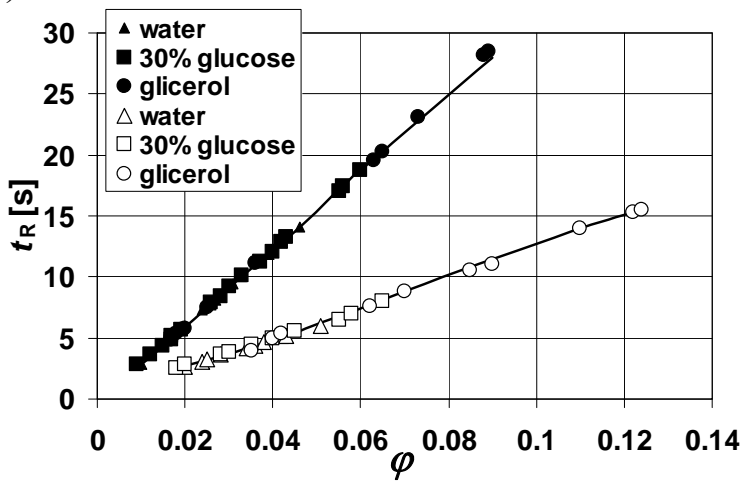

Fig. 9. The dependence a) $\varphi=f\left(P_{\mathrm{g}} / V_{\mathrm{L}}\right)$, b) $t_{\mathrm{R}}=f(\varphi)$ for gas - liquid system agitated by means of CD 6 (lower) - RT impellers system; $D=0.288 \mathrm{~m} ; i=2 ; H / D=2$; planar baffles; $J=4 ; B / D=0.1$; a) $\left.w_{\mathrm{og}}=5.2 \times 10^{-3} \mathrm{~m} / \mathrm{s} ; \mathrm{b}\right)$ filled points, $w_{\mathrm{og}}=3.4 \times 10^{-3} \mathrm{~m} / \mathrm{s}$; empty points $w_{\mathrm{og}}=5.2 \times 10^{-3} \mathrm{~m} / \mathrm{s}$

In mechanically agitated gas - liquid systems, gas hold-up $\varphi$ significantly depends on the impeller baffle system and physical properties of the fluid (viscosity, surface tension, capability of gas bubbles to coalesce). The parameter $Y$, discussed by Major-Godlewska and Karcz (2011), can be understood as the ability of gas bubbles to coalesce $(Y=1$ corresponds to coalescing gas - liquid systems, whereas $Y$ $>1$ describes non-coalescing systems, Eq. (7) in Table 2). The experimental data in Fig. 9a, obtained for the system with two impellers (CD 6 in the lower position and Rushton turbine - in the upper one) operating at the vessel with planar baffles, show that for a constant value of the specific power consumption $P_{\mathrm{g}} / V_{\mathrm{L}}$ the lowest values of $\varphi$ are observed for the air - distilled water system, whereas the highest $\varphi$ values are observed for the air $-60 \%$ starch syrup. The first gas - liquid system shows the ability of gas bubbles to coalesce in the liquid, whereas this ability is significantly decreased for the second physical system. As the data in Fig. $9 \mathrm{~b}$ present, the mean average residence time $t_{\mathrm{R}}$, defined as follows $t_{\mathrm{R}}=V_{\mathrm{L}} \varphi /\left[\dot{V}_{g}(1-\varphi)\right]$, is a linear function of gas hold-up $\varphi$ for different liquids and $t_{\mathrm{R}}$ value increases with decreasing superficial gas velocity $w_{\text {og }}$. Gas hold-up $\varphi$ increases with rising $w_{\text {og }}$ values (Fig. 10). In the three phase air - yeast - aqueous solution of a sucrose system agitated in a vessel equipped with CD 6 impeller and standard planar baffles (Fig.10a), values of the gas hold-up $\varphi$ increase with the increase of yeast concentration. A comparison of data obtained for three different impellers: Rushton turbine RT, CD 6 and A 315 impellers shows that the highest values of $\varphi$ correspond to the Rushton turbine, whereas the lowest ones to the A 315 impeller. 
Table 2. Equations used to analyse effects of different factors on momentum transfer in mechanically agitated multiphase systems (range of equations is given in Table 1)

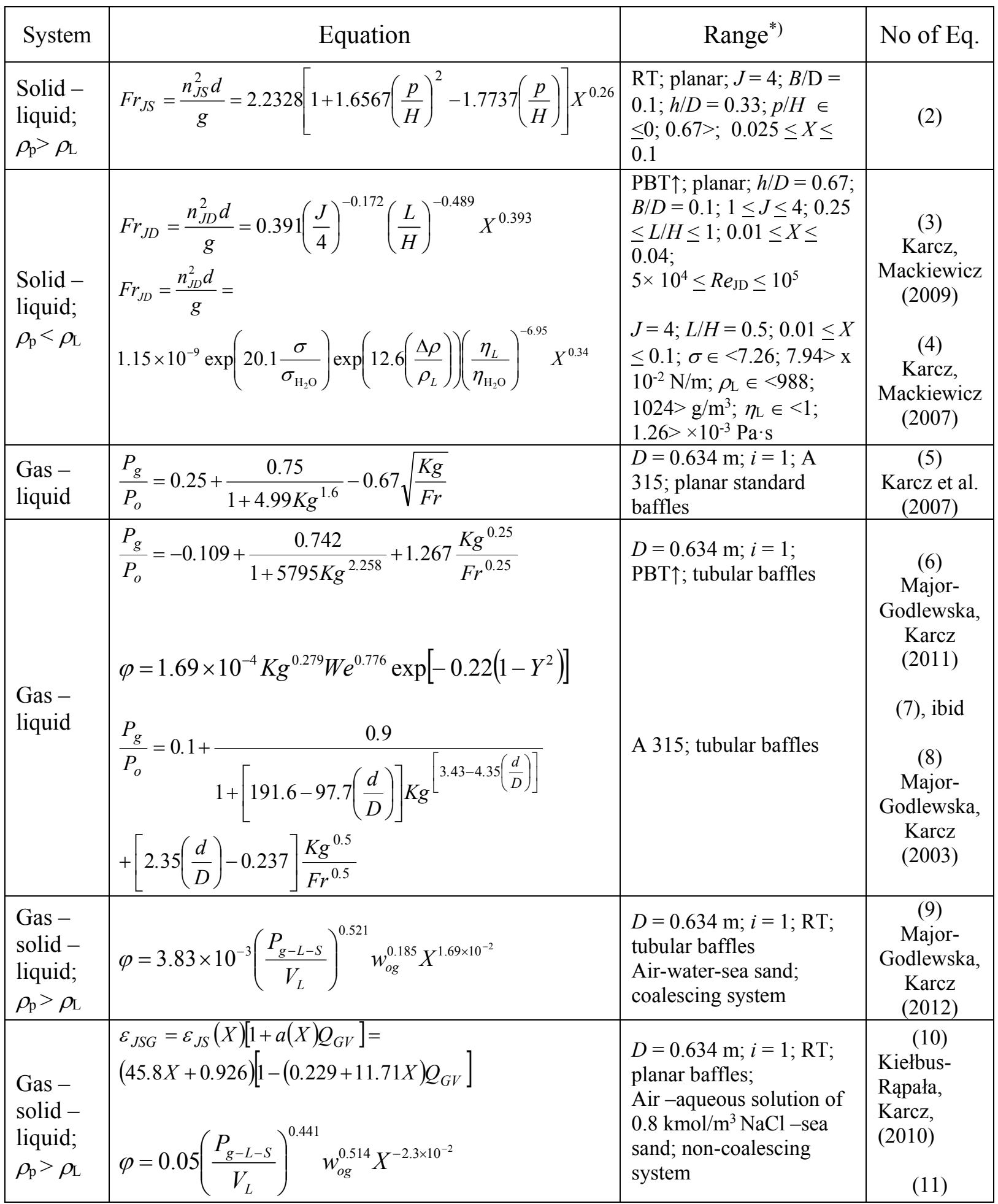

${ }^{*}$ Other details are given in Table 1

A comparison of $\varphi=\mathrm{f}\left(P / V_{\mathrm{L}}\right)$ obtained for gas - liquid systems differing in their capability of gas bubbles to coalesce and agitated using different single impellers in vessels equipped with the planar or tubular baffles is shown in Fig. 11. For a given level of the specific power consumption $P / V_{\mathrm{L}}$ in the vessel with planar baffles (Fig. 11a), the values of $\varphi$ increase with the increase of the parameter $Y$. A similar correlation is observed for the agitated vessel equipped with tubular baffles, assuming constant values of the impeller speed $n$ and specific agitation energy $P / V_{\mathrm{L}}$ for a given impeller type. The 
introduction of solids with concentration $X$ to the gas - liquid system slightly affects the gas hold-up $\varphi$ values in both agitated vessels with tubular and planar baffles (Eqs. (9) and (11) in Table 2).

a)

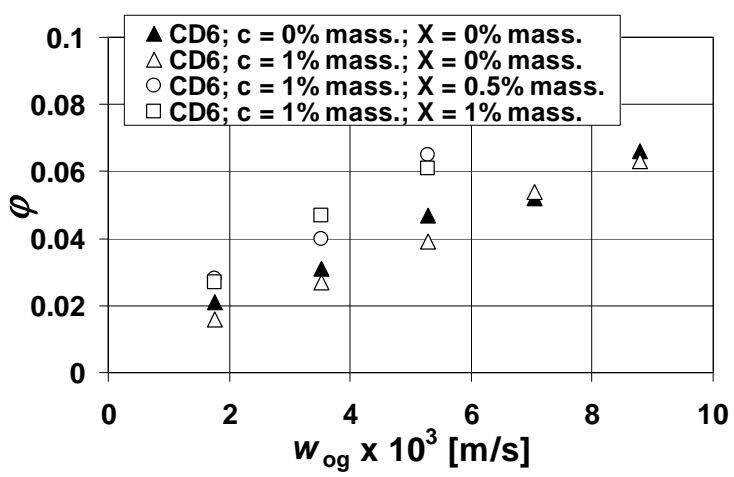

b)

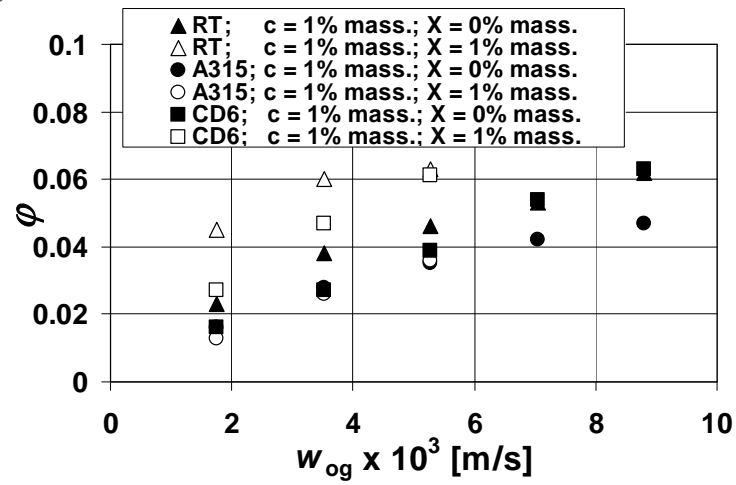

Fig. 10. The dependence $\varphi=f\left(w_{\mathrm{og}}\right)$ for the air - yeast - aqueous solution of sucrose system; $n=51 / \mathrm{s}$; $D=0.634 \mathrm{~m} ; i=1 ; H / D=1 ; d / D=0.33 ; h / D=0.33$; planar baffles, $J=4 ; L / H=1 ; B / D=0.1$

a)

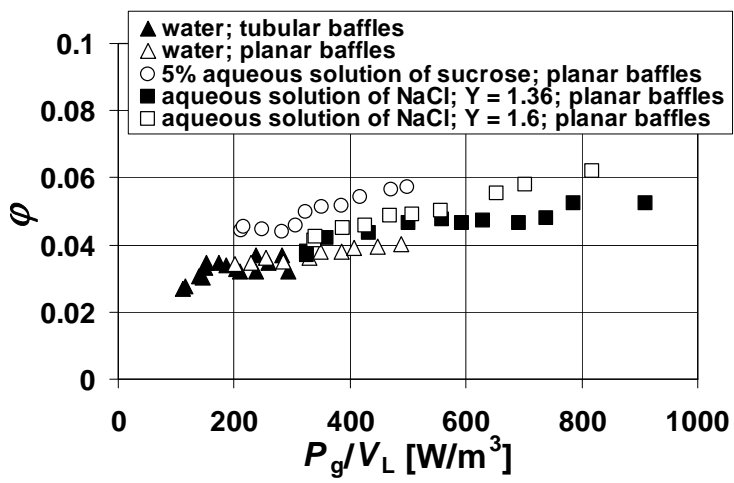

b)

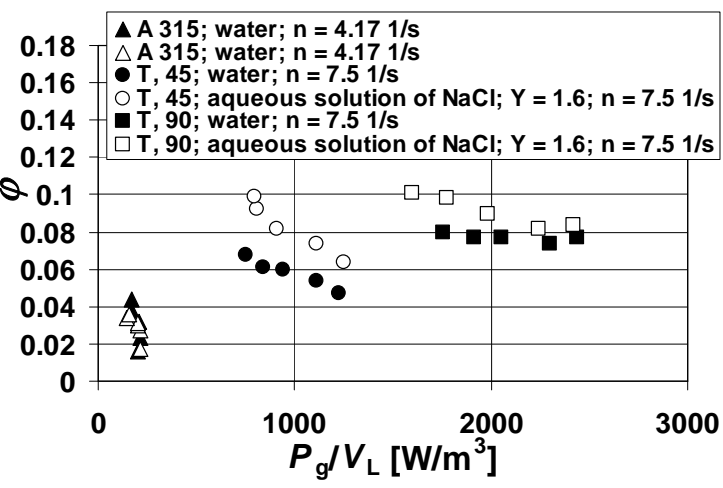

Fig. 11. The dependence $\varphi=f\left(P / V_{\mathrm{L}}\right)$ for the air - liquid system; $D=0.634 \mathrm{~m} ; H / D=1 ; d / D=0.33$; a) A 315; b) tubular baffles $(\boldsymbol{\Lambda}, \bullet, \mathbf{\square}, \circ, \square)$; planar baffles $(\Delta)$; T, $45-$ turbine $\mathrm{T}\left(\beta=45^{\circ}\right)$; T, 90 - turbine $\mathrm{T}\left(\beta=45^{\circ}\right)$

\section{CONCLUSIONS}

A comparative analysis on the influence of different factors on momentum transfer in mechanically agitated multiphase systems was carried out on the basis of our experimental results, which were generalised in Eqs (2) - (11). The applicability ranges of Eqs. (2) - (11) are listed in Table 1. Our comparative analysis, justified experimentally, can be summarised as follows:

- Many aspects, including the geometry of the impeller - baffle system, the scale of the agitated vessel, the type and number of impellers and their off-bottom clearance, as well as physical properties of a multiphase system should be considered simultaneously in order to enable appropriate conditions to suspend or draw down particles, as well as to disperse gas bubbles in a liquid phase or a two-phase system.

- Critical impeller speeds (minimum impeller speeds) $n_{\mathrm{JS}}, n_{\mathrm{JSG}}, n_{\mathrm{JD}}, n_{\mathrm{JDG}}$ are not a sufficient criterion to evaluate the state of a multiphase system. Froude numbers $F r_{\mathrm{IS}}, F r_{\mathrm{ID}}$ can be considered as a better measure because the Froude number takes also into account the impeller dimension. However, the most reliable criterion corresponds to the agitation energy $\left(\varepsilon[\mathrm{W} / \mathrm{kg}]\right.$ or $\left.P / V\left[\mathrm{~W} / \mathrm{m}^{3}\right]\right)$ which is needed to produce a multiphase system. 
- Any change of a single factor (ascribed to the impeller, baffles or physical properties of a multiphase system) can radically affect the behaviour of a mechanically agitated un-gassed or gassed suspension.

- Gas hold-up in a mechanically agitated gas - liquid or gas - solid - liquid system significantly depends on the physical properties of the fluid. The highest values of $\varphi$ correspond to the noncoalescing systems.

\section{SYMBOLS}

$a$

$B$

$B$

$c$

$d$

$d_{d}$

$d_{p}$

$d_{o}$

$D$

$D_{c}$

e

$H$

$H_{g}$

$h$

$i$

$J$

$L$

$n$

$n_{J S, J S G}$

$n_{J D, J D G}$

$p$

$P_{o}$

$P_{g}$

$Q_{G V}$

$S$

$t_{R}$

$V_{L}$

$\dot{V}_{g}$

$w_{o g}$

$X$

$Y$

Z

length of impeller blade, $\mathrm{m}$

baffle width, $m$

width of impeller blade, $\mathrm{m}$

sucrose concentration, $\%$ mass

impeller diameter, $\mathrm{m}$

diameter of gas sparger, $\mathrm{m}$

particles diameter, $\mathrm{m}$

diameter of impeller disc, $m$

inner diameter of agitated vessel, $\mathrm{m}$

mean coil diameter (diameter of tubular baffles), $\mathrm{m}$

off-bottom clearance of gas sparger, $\mathrm{m}$

liquid height in agitated vessel, $\mathrm{m}$

the height of a gas-liquid mixture in agitated vessel, $\mathrm{m}$

off-bottom clearance of impeller, $\mathrm{m}$

number of impellers

number of baffles

length of baffle, $m$

impeller speed, $1 / \mathrm{s}$

critical impeller speed, $1 / \mathrm{s}$

just drawdown impeller speed, $1 / \mathrm{s}$

distance of short baffle from vessel bottom, $\mathrm{m}$

power consumption for liquid phase, $\mathrm{W}$

power consumption for the gas-liquid system, $\mathrm{W}$

volumetric gas flow rate, $\left(\mathrm{m}^{3} / \mathrm{min}\right) / \mathrm{m}^{3}$

pitch of the propeller

gas residence time, $\mathrm{s}$

volume of the liquid in the vessel, $\mathrm{m}^{3}$

gas flow rate, $\mathrm{m}^{3} / \mathrm{s}$

superficial gas velocity, $=4 \dot{V}_{g} / \pi D^{2}, \mathrm{~m} / \mathrm{s}$

mass fraction of particles or yeast concentration, , $\%$ mass

parameter, measure of the ability of gas bubbles to coalesce

number of impeller blades

Greek symbols

$\beta \quad$ pitch of impeller blade, deg

$\varepsilon \quad$ energy dissipated, $\mathrm{W} / \mathrm{kg}$

$\eta \quad$ viscosity, $\mathrm{Pa} \cdot \mathrm{s}$

$\varphi \quad$ gas hold-up

$\rho \quad$ density, $\mathrm{kg} / \mathrm{m}^{3}$

$\sigma \quad$ surface tension, $\mathrm{N} / \mathrm{m}$ 


$\begin{array}{ll}\text { Subscripts } & \\ g & \text { refers to gas phase } \\ L & \text { refers to liquid phase } \\ P & \text { refers to solid phase } \\ J D & \text { just drawdown } \\ J D G & \text { just drawdown under gassed conditions } \\ J S & \text { just suspended } \\ J S G & \text { just suspended under gassed conditions }\end{array}$

Dimensionless numbers

$F r=\frac{n^{2} d}{g} \quad$ Froude number

$K g=\frac{\dot{V}_{g}}{n d^{3}} \quad$ gas flow number

$R e=\frac{n d^{2} \rho_{L}}{\eta_{L}}$ Reynolds number

$W e=\frac{n^{2} d^{3} \rho_{L}}{\sigma_{L}}$ Weber number

\section{REFERENCES}

Adamiak R., 2005. Experimental studies of conditions for gas dispersion in liquid in the stirred tank on different scale. PhD Thesis, Politechnika Szczecińska, Szczecin (in Polish).

Adamiak R., Karcz J., 2007. Effects of type and number of impellers and liquid viscosity on the power characteristics of mechanically agitated gas-liquid systems. Chem. Pap., 61, 16-23. DOI: 10.2478/s11696-0060089-6.

Bao Y., Hao Z. Gao Z., Shi L., Smith J.M., 2005. Suspension of buoyant particles in a three phase stirred tank. Chem. Eng. Sci., 60, 2283-2292. DOI: 10.1016j.ces.2005.10040.

Cudak M., 2011. Process characteristics for the mechanically agitated gas-liquid systems in the turbulent fluid flow. Przem. Chem., 90, 1628-1632 (in Polish).

Cudak M., 2014. Hydrodynamic characteristics of mechanically agitated air-aqueous sucrose solutions. Chem. Process Eng., 35, 1, 97-107. DOI: 10.2478/cpe-2014-0007.

Etchells A.W., 2001. Mixing of floating solids. Plenary Lecture. Proceedings of the $4^{\text {th }}$ International Symposium on Mixing in Industrial Processes ISMIP 4, 14-16 May 2001, Toulouse, France.

Harnby N., Edwards M.F., Nienow A.W., 1992. Mixing in the process industries, Butterworth-Heineman, Oxford, UK.

Kamieński J., 2004. Agitation of multiphase systems. WNT, Warszawa (in Polish).

Kamieński J., Niżnik J., 2001. Gas hold-up for gas-liquid system agitated with dual impellers. Inż. Chem. Proc., 22, 3C, 597-603 (in Polish).

Karcz J., Adamiak R., Kiełbus-Rąpała A., 2007. Agitation of gas-liquid systems. Scale-up effects on the process characteristics. Chem. Process Eng., 28, 93-113.

Karcz J., Mackiewicz B., 2006. Suspending of floating solids in an agitated vessel. Chem. Process Eng., 27, 1517-1533.

Karcz J., Mackiewicz B., 2007. An effect of particles wettability on the draw down of floating solids in a baffled agitated vessel equipped with a high-speed impeller. Chem. Process Eng., 28, 661-672.

Karcz J., Mackiewicz B., 2009. Effects of vessel baffling on the drawdown of floating solids. Chem. Pap., 63, 2, 164-171. DOI: 10.2478/s11696-009-0011-0.

Karcz J., Siciarz R., 2004. An analysis of the stirred tank scale on the gas-liquid dispersion In the tank with single or dual impellers. Inż. Chem. Proc., 25, 1075-1081 (in Polish). 
Karcz J., Siciarz R., Bielka I., 2004. Gas hold-up in a reactor with dual system of impellers. Chem. Pap., 58, 404409.

Kiełbus-Rąpała A., Karcz J., 2010. Solid suspension and gas dispersion in gas-solid-liquid agitated systems. Chem. Pap. 64, 2, 154-162. DOI: 10.2478/s11696-009-0104-9.

Kiełbus-Rapała A., Karcz J., 2012. Experimental analysis of the hydrodynamics of a three-phase systems in a vessel with two impellers. Chem. Pap., 66, 6, 574-582. DOI: 10.2478/s11696-012-0157-z.

Kiełbus-Rapała A., Karcz J., Cudak M., 2011. The effect of the physical properties of the liquid phase on the gasliquid mass transfer coefficient in two- and three-phase agitated systems. Chem. Pap., 65, 2, 185-192. DOI: 10.2478/s11696-011-0004-7.

Major-Godlewska M., Karcz J., 2003. Gas hold-up and power consumption for gas-liquid system agitated in a stirred tank equipped with vertical coil. Chem. Pap., 57, 432-437.

Major-Godlewska M., Karcz J., 2012. Agitation of a gas-solid-liquid system in a vessel with high-speed impeller and vertical tubular coil. Chem. Pap., 66, 6, 566-573. DOI: 10.2478/s11696-012-0148-0.

Major-Godlewska M., Karcz J., 2011. Process characteristics for gas-liquid system agitated in a vessel equipped with a turbine impeller and tubular baffles. Chem. Pap., 65, 132-138. DOI: 10.2478//S11696-010-0080-0.

Montante G., Horn D., Paglianti A., 2006. Gas-liquid flow and bubble size distribution in stirred tanks. Chem. Eng. Sci., 63, 2107-2118. DOI: 10.1016/j.ces.2008.01.005.

Montante G., Paglianti A., Magelli F., 2007. Experimental analysis and computational modeling of gas-liquid stirred vessels. Chem. Eng. Res. Des., 85, 647-653. DOI: 10.1205/cherd06141.

Moucha T., Linek V., Prokopowa E., 2003. Gas hold-up, mixing time and gas-liquid volumetric mass transfer coefficient of various multiple-impeller configurations: Rushton turbine, pitched blade and techmix impeller and their combinations. Chem. Eng. Sci., 58, 1839-1846. DOI: 10.1016/S0009-2509(02)00682-6.

Nienow A.W., 1968. Suspension of solid particles in turbine agitated baffled vessels. Chem. Eng. Sci., 23, 12, 1453-1459. DOI: 10.1016/0009-2509(68)89055-4.

Nienow A.W., Lilly M.D., 1996. Gas-liquid mixing studies: A comparison of Rushton turbines with some modern impellers. Trans IChemE, 74A, 417-423.

Ozcan-Taskin G., 2006. Effect of scale on the draw down of floating solids. Chem. Eng. Sci., 60, 2871-2879. DOI: $10.1016 /$ j.ces.2005.10.061.

Ozcan-Taskin G., Wei H., 2003. The effect of impeller-to-tank diameter ratio on draw down of solids. Chem. Eng. Sci., 58, 2011-2022. DOI: 10.1016/S0009-2509(03)00024-1.

Paul E.L., Atiemo-Obeng V.A., Kresta S.M., 2004. Handbook of Industrial Mixing. Wiley-Interscience, Hoboken, New Jersey.

Rieger F., Ditl P., 1994. Suspension of solid particles. Chem. Eng. Sci., 49, 14, 2219-2227. DOI: 10.1016/00092509(94)E0029-P.

Stręk F., 1981. Agitation and agitated vessels. WNT, Warszawa (in Polish).

Takenaka K., Ciervo G., Monti D., Bujalski W., Etchells A.W., Nienow A.W., 2001. Mixing of three-phase systems at high solid content (up to $40 \% \mathrm{w} / \mathrm{w}$ ) using radial and mixed flow impellers. J. Chem. Eng. Japan, 34, 606-612. DOI: 10.1252/jcej.34.606.

Warmoeskerken M.M.C.G., 1986. Gas-liquid dispersing characteristics of turbine agitators. PhD thesis, Technische Hogeschool Delft, The Netherlands.

Zhu Y., Wu J., 2002. Critical impeller speed for suspending solids in aerated agitation tanks. Canadian J. Chem. Eng., 80, 1-5. DOI: 10.1002/cjce.5450800417.

Zwietering T.N., 1958. Suspending of solids particles in liquid by agitation. Chem. Eng. Sci., 8, 244-253. DOI: $10.1016 / 0009-2509(58) 85031-9$. 